\section{Letters to Editor}

\section{False positive results with Pregnosticon pregnancy test}

The experience of Dr Hunter and Mr Gray with Pregnosticon,' a haemagglutination inhibition test for pregnancy, is of interest. It is not clear from their account whether the eight positive Pregnosticon reactions occurred on the same day and with the same batch of reagents. In our laboratory specimens are occasionally received which cause a partial inhibition of haemagglutination. Such reactions are not recorded as positive and the tests are repeated the next day, when the result has always been correctly negative.

Immunological pregnancy tests can be affected adversely by non-specific factors, including detergents. About 5000 of the 20000 specimens received annually come in bottles, usually without, but not always, some of their former contents. Hair shampoo bottles are popular, and urines from these may interfere with the normal test reaction.

We have used Pregnosticon since 1963 and tested more than 405000 urines with this reagent. The overall accuracy of the test, based on the clinical diagnosis for 52606 women, is $98.7 \%$ with an accuracy of $98 \cdot 1-100 \%$ between 21 batches. Analysis of the results shows that a positive result in the absence of clinical evidence of pregnancy might be expected once in $\mathbf{2 6 0 0}$ tests. As information accumulates about the incidence of menstrual and very early abortions the probability that these false positives are correct must also be considered.

In a recent comparative study between a slide test (Pregnosticon Neoplano Duoclon, sensitivity 500 IU human chorionic gonadotrophin/l) and a haemagglutination inhibition test (Pregnosticon "ALL-in," sensitivity 1000 IU human chorionic gonadotrophin/l) there was complete agreement between the two tests in 993 of 1015 urines. The difference was due to 22 urines giving a positive Neoplano, negative Pregnosticon reaction. Clinical diagnosis subsequently confirmed that the 22 urines were from women with early pregnancies. The less sensitive haemagglutination inhibition test was never positive when the more sensitive direct latex agglutination test was negative.

BM HOBSCN

Centre for Reproductive Biology,

Reproductive Endocrinology Laboratory, Department of Obstetrics and Gynaecology, University of Edinburgh, Edinburgh

\section{Reference}

' Hunter P, Gray SJ. False positive results with Pregnosticon pregnancy test. J Clin Pathol 1984:37: 1079 .

\section{Susceptibility of Campylobacter spp to inks}

I read with interest the article by $\mathrm{Mr}$ Bolton and his colleagues, ${ }^{\prime}$ in which they described the susceptibility of Campylobacter spp to various dyes and chemicals for use in a biotyping scheme.

I should like to report an observation I made during a similar investigation. Eight strains consisting of Campylobacter jejuni, Campylobacter coli, and Campylobacter laridis were streaked across blood agar (Lab M-WBA) test plates. Bacteruritest dipstrips (Mast) which had been soaked in undiluted writing ink (Super Quink; Parker Pen Co Ltd) and dried were placed on the agar surface at right angles to the bacterial streaks. All plates were incubated microaerobically at $37^{\circ} \mathrm{C}$ for $48 \mathrm{~h}$. Growth of the eight strains was not affected by the green, red, or royal blue inks, but all were inhibited by the black ink. After discussions with the manufacturer, the most likely difference between these inks is either the formulation of the biocide or the $\mathrm{pH}$. Other workers may consider that this observation is worthy of further investigation with a larger number of strains.

This work was carried out at the Luton Public Health Laboratory.

EP WRIGHT
Department of Microbiology,
Royal East Sussex Hospital,
Hastings, East Sussex.

\section{Reference}

' Bolton FJ, Holt AV, Hutchinson DN. Campylobacter biotyping scheme of epidemiological value. J Clin Pathol 1984;37:677-81.

Small intestinal mucosal fat in childhood enteropathies

We read with interest the article by Variend et al" entitled "small intestinal mucosal fat in childhood enteropathies." The authors state that "mucosal fat in small intestinal disease has not been previously investigated."
We presented a paper at the IXth European Congress of Pathology held at Ham- 0 burg in September 1983 on "Lipids in $\frac{2}{5}$ enterocytes". We found lipid vesicles in 은 the enterocytes of three adult patients suffering from diarrhoea with steatorrhoea. $\stackrel{\vec{P}}{+}$ Electron microscopical studies showed that 0 the lipid vesicles were partly membrane $\frac{\sigma}{\sigma}$ bound and were in close relation with the $\overline{\bar{\omega}}$ smooth endoplasmic reticulum, less often $\vec{D}$ in the Golgi region. The aetiology of this condition remains obscure.

Puzzled by these findings, we reviewed the endoscopic and tube biopsies of the duodenum and jejunum examined at our $\vec{\omega}$ department during 1982. Of a total of 650 D biopsies, we screened those with villous atrophy in coeliac disease (new and treated cases) and found lipids in the enterocytes. of 10 adults and three children.

From the studies of Riley and Glickman ${ }^{3}$. we suggest that the accumulation of lipids $\overrightarrow{0}$ in the smooth endoplasmic reticulum is ${ }_{1}$ probably due to a disturbance of tri-

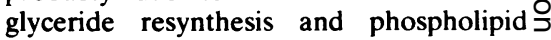
reacylation; their presence in the Golgi apparatus would indicate a disturbance in $\bigcirc$ their glycosylation. Department of Pathology, University Hospitg, $\vec{\omega}$ 1211 Genève童 Switzerlam

\section{References}

' Variend S, Placzek M. Raafet F, Walker Smith JA. Small intestinal mucosal fat in childhood enteropathies. J Clin Pathol 1984;37:373-7. 气

${ }^{2}$ Widgren S. Bergoz R, Voirol M. Lipids in $\overrightarrow{\overline{0}}$ enterocytes. Path Res Pract 1983;178:173.

${ }^{3}$ Riley JW, Glickman RM. Fat malabsorption. Advances in our understanding. Am J Med 1979:67:980.

\section{On the naming of dyes}

Today's histologists are becoming more colour conscious. Modern colour film 윽 entices them to experiment with dyes invented since the days of van Gieson, Mallory, Heidenhain, and Masson.

In the time of those leaders there was no directory or index of dyes other than $N$ Schultz's Farbstoffiabellen. This has been $\mathrm{N}$ largely superseded by the Anglo-American $\omega$ Colour Index, now in its 3rd edition.' The latter, with its mass of international infor- $c$ mation, skilfully classified and arranged, is $\overparen{\complement}$ kept up to date with supplements. It is, however, very costly. Fortunately, much of 